\title{
Urea Orientation at Protein Surfaces
}

\author{
Xin Chen, Laura B. Sagle, and Paul S. Cremer ${ }^{\star}$ \\ Department of Chemistry, Texas A\&M University, P.O. Box 30012, College Station, Texas 77843 \\ Tel: 979-862-1200, Fax : 979-845-7561
}

\begin{abstract}
We have exploited the unique ability of vibrational sum frequency spectroscopy (VSFS) to investigate interfacial urea molecules at protein surfaces. Experiments were carried out at the bovine serum albumin/water interface. The absolute orientation of interfacial urea could be followed directly by VSFS. It was found that urea orients with its $\mathrm{NH}$ groups pointing toward the protein at high $\mathrm{pH}$, where the protein is negatively charged. The orientation flips at low $\mathrm{pH}$, where the protein is positively charged. This behavior resembles that of interfacial water. The direct interactions between urea and proteins should be electrostatic in nature and, therefore, very sensitive to the charge state of the protein. Urea denaturation of proteins, however, is not sensitive to charge, which is inconsistent with a direct interaction mechanism.
\end{abstract}

Urea facilely denatures proteins in aqueous solution. Despite its extensive use, the molecular mechanism of this process remains unclear. ${ }^{1,2}$ Most of the literature in this area can be summarized into two major models: the direct mechanism and the indirect mechanism. According to the direct mechanism, urea can "bind" to proteins through hydrogen bonding and/or other electrostatic interactions. By contrast, the indirect mechanism posits that urea weakens hydrophobic interactions by perturbing water structure, so that hydrophobic residues become better solvated.

Although there has been an increasing number of theoretical simulations dedicated to understanding urea denaturation, ${ }^{2}$ fewer experimental studies have recently been undertaken to address the molecular level details of this problem. Experiments in bulk urea solution suggest that this molecule has little-to-no effect on bulk water structure or the effect is not related to protein denaturation. ${ }^{3}$ On the other hand, it is well established that urea accumulates at the protein/solution interface. ${ }^{4}$ Therefore, it is crucial to investigate interfacial urea molecules and their direct and indirect interactions with proteins. Very few experimental techniques, however, directly probe interfacial urea. Using vibrational sum frequency spectroscopy (VSFS), ${ }^{5-7}$ we investigated interfacial urea molecules residing at the bovine serum albumin (BSA)/water interface. VSFS, an intrinsically surface-specific technique, is perfectly suitable for this task. A molecule must be preferentially orientated to be active in VSFS. The net orientation of the transition dipole moment of a vibrational mode can be either up or down along the surface normal, and is commonly represented with a "+" or "--" sign, respectively. Therefore, the absolute orientation of interfacial urea can be directly measured. To the best of our knowledge, this is the first time that urea has been specifically probed at the protein/water interface. Our results indicate that its absolute orientation depends on the sign of the charge at the interface. Such a result is more consistent with an indirect urea denaturation mechanism as will be discussed. 
First, VSFS spectra were measured next to a saturated monolayer of BSA adsorbed at the air/ aqueous solution interface at various $\mathrm{pH}$ values with $0 \mathrm{M}$ urea, Figure 1a. These experiments were repeated under the identical conditions with an $8 \mathrm{M}$ urea solution in the subphase, Figure 1b. The spectral fits of the $\mathrm{CH}, \mathrm{OH}$, and $\mathrm{NH}$ stretches are shown to the right of these spectra (see Supporting Information for details). The spectra at $0 \mathrm{M}$ urea give rise to a group of peaks between $2800 \sim 3050 \mathrm{~cm}^{-1}$, (black dashed curves in the fitted column), which can be assigned to $\mathrm{CH}$ vibrations and their Fermi resonances originating from the hydrophobic residues of BSA. 8 These peaks are not significantly changed with $\mathrm{pH}$. The two broad peaks at $\sim 3200 \mathrm{~cm}^{-1}$ and $\sim 3425 \mathrm{~cm}^{-1}$, (blue curves in the fitted column) are commonly assigned to interfacial water with a more complete and less complete hydrogen bonding network, respectively. 6,7 Unlike the $\mathrm{CH}$ peaks, the water peaks are extremely sensitive to $\mathrm{pH}$. In fact, strong intensity can only be observed when the $\mathrm{pH}$ value is significantly higher or lower than the isoelectric point of BSA, $\sim \mathrm{pH} 5.0 .^{9}$ At the isoelectric point, the water features nearly vanish. More importantly, these peaks carry a negative sign at high $\mathrm{pH}$ and a positive sign at low $\mathrm{pH}$, indicating that orientation of the interfacial water molecules flips. Similar observations were made in previous VSFS studies of BSA as well as other proteins. ${ }^{8}$

When $8 \mathrm{M}$ urea was introduced to the solution, a new peak at $\sim 3368 \mathrm{~cm}^{-1}$ arose, Figure $1 \mathrm{~b}$, (red curves in the fitted column). This feature is significantly sharper than the $\mathrm{OH}$ vibrations. Judging from its position and shape, it is almost certainly an NH stretch mode. In fact, peaks with very similar shapes and positions $\left(\sim 3380 \mathrm{~cm}^{-1}\right)$ have been reported before by our laboratory 10 and others, ${ }^{11}$ and assigned to $\mathrm{NH}$ stretches. Such an assignment is consistent with IR and Raman spectra where the NH stretch of urea is observed near this frequency. ${ }^{12}$ Herein, we assign this peak to an NH stretch from urea.

As shown in Figure 1b, both the $\mathrm{NH}$ and $\mathrm{OH}$ vibrations adopt a negative sign at $\mathrm{pH} 9$. Assuming that the transitional dipole moment of the $\mathrm{NH}$ from urea faces the same direction as the $\mathrm{OH}$ from water (since both $\mathrm{N}$ and $\mathrm{O}$ are much more electronegative than $\mathrm{H}$ ), then the $\mathrm{NH}$ and $\mathrm{OH}$ groups must point in the same direction. Specifically, both interfacial urea and water should be oriented with their hydrogen bonds pointing toward the protein and the oxygen pointing away from it (Figure 2a). The urea peak attenuates with decreasing $\mathrm{pH}$, indicating that the osmolyte becomes increasingly less orientated as the solution is made more acidic. At $\mathrm{pH} 5$, virtually no intensity from the urea peak can be detected, which implies that the urea molecules are essentially randomly oriented. When the $\mathrm{pH}$ was further lowered to 3 , the urea peak rose again. This time, however, it carries a positive sign, indicating that urea now orients in the opposite direction (Figure 2b). In other words, interfacial urea flips its orientation as the system goes through the isoelectric point in a manner very similar to water.

It is well established that interfacial water is very sensitive to the charge state of the protein. 7,8 The electrostatic interactions, especially ion-dipole interactions, dictate the orientation of the interfacial water molecules. When the protein is at its isoelectric point, interfacial water orientation is minimal. The interactions responsible for urea orientation should certainly be electrostatic in nature as well.

The flipping of interfacial urea molecules with surface charge has a couple of important implications. First, the change in orientation should perturb the hydrogen bonding between urea and the protein. Specifically, urea probably goes from being a hydrogen bond donor with $\mathrm{NH}_{2}$ groups facing toward the protein at high $\mathrm{pH}$, to being a hydrogen bond acceptor with the same groups facing away from the protein at low $\mathrm{pH}$ (Figure 2). Second, flipping the molecule's orientation should strongly affect adjacent water molecules and their bonding. Indeed, the fitted oscillator strengths of the $3200 \mathrm{~cm}^{-1}$ and $3425 \mathrm{~cm}^{-1}$ water peaks were altered by the addition of urea (Figure 1). 
It is well known that urea is a highly effective denaturant for proteins both above and below their isoelectric points. ${ }^{13}$ Since this molecule flips its orientation with the modulation of the interfacial charge, it is difficult to envision a mechanism by which electrostatic interactions or specific hydrogen bonds between urea and proteins are directly responsible for protein denaturation. On the other hand, an indirect mechanism is consistent with the current results. Namely, urea molecules affect the hydrogen bonding of interfacial water molecules. This altered solution environment, in turn, affects the solvation of the proteins.

Further studies are currently underway in our laboratory to quantitatively understand changes in the alignment of interfacial urea and water molecules as a function of solution conditions.

\section{Supplementary Material}

Refer to Web version on PubMed Central for supplementary material.

\section{Acknowledgements}

We thank the Robert A. Welch Foundation (Grant A-1421) and the National Institutes of Health (GM070622) for funding.

\section{References}

1. For example, see: (a) Robinson DR, Jencks WP. J Am Chem Soc 1965;87:2462-2470. [PubMed: 14330716] (b) Pace NC, Tanford C. Biochemistry 1968;7:198-208. [PubMed: 5758543] (c) Tanford C. J Am Chem Soc 1964;86:2050-2059. (d) Schellman JA. Biopolymers 1978;17:1305-1322. (e) Alonso DOV, Dill KA. Biochemistry 1991;30:5974-5985. [PubMed: 2043635] (f) Auton M, Bolen DW. Proc Natl Acad Sci U S A 2005;102:15065-15068. [PubMed: 16214887] (g) Auton M, Ferreon ACM, Bolen DW. J Mol Biol 2006;361:983-992. [PubMed: 16889793] (h) Rosgen J, Pettitt BM, Bolen DW. Protein Sci 2007;16:733-743. [PubMed: 17327389]

2. For example, see: (a) Kuharski RA, Rossky PJ. J Am Chem Soc 1984;106:5794-5800. (b) TiradoRives J, Orozco M, Jorgensen WL. Biochemistry 1997;36:7313-7329. [PubMed: 9200680] (c) Bennion BJ, Daggett V. Proc Natl Acad Sci U S A 2003;100:5142-5147. [PubMed: 12702764] (d) Lee ME, van der Vegt NFA. J Am Chem Soc 2006;128:4948-4949. [PubMed: 16608317] (e) Camacho CJ, Thirumalai D. Protein Sci 1996;5:1826-1832. [PubMed: 8880906] (f) Tobi D, Elber R, Thirumalai D. Biopolymers 2003;68:359-369. [PubMed: 12601795] (g) Mountain RD, Thirumalai D. J Am Chem Soc 2003;125:1950-1957. [PubMed: 12580622]

3. (a) Batchelor JD, Olteanu A, Tripathy A, Pielak GJ. J Am Chem Soc 2004;126:1958-1961. [PubMed: 14971928] (b) Rezus YLA, Bakker HJ. Proc Natl Acad Sci U S A 2006;103:18417-18420. [PubMed: 17116864]

4. Courtenay ES, Capp MW, Record MT. Protein Sci 2001;10:2485-2497. [PubMed: 11714916]and references therein

5. Shen, YR. The Principles of Nonlinear Optics. Wiley; New York: 1984.

6. Richmond GL. Chem Rev 2002;102:2693-2724. [PubMed: 12175265]

7. Shen YR, Ostroverkhov V. Chem Rev 2006;106:1140-1154. [PubMed: 16608175]

8. (a) Wang J, Buck SM, Chen Z. J Phys Chem B 2002;106:11666-11672. (b) Kim G, Gurau M, Kim J, Cremer PS. Langmuir 2002;18:2807-2811.

9. Theodore Peters, J. All about Albumin. Academic Press; New York: 1996.

10. Jung SY, Lim SM, Albertorio F, Kim G, Gurau MC, Yang RD, Holden MA, Cremer PS. J Am Chem Soc 2003;125:12782-12786. [PubMed: 14558825]

11. (a) Mermut O, Phillips DC, York RL, McCrea KR, Ward RS, Somorjai GA. J Am Chem Soc 2006;128:3598-3607. [PubMed: 16536533] (b) Wang J, Chen XY, Clarke ML, Chen Z. J Phys Chem B 2006;110:5017-5024. [PubMed: 16526745] (c) Clarke ML, Wang J, Chen Z. J Phys Chem B 2005;109:22027-22035. [PubMed: 16853860] 
12. (a) Stewart JE. J Chem Phys 1957;26:248-254. (b) Otvos JW, Edsall JT. J Chem Phys 1939;7:632632.

13. Myers JK, Pace CN, Scholtz JM. Protein Sci 1995;4:2138-2148. [PubMed: 8535251]and references therein 

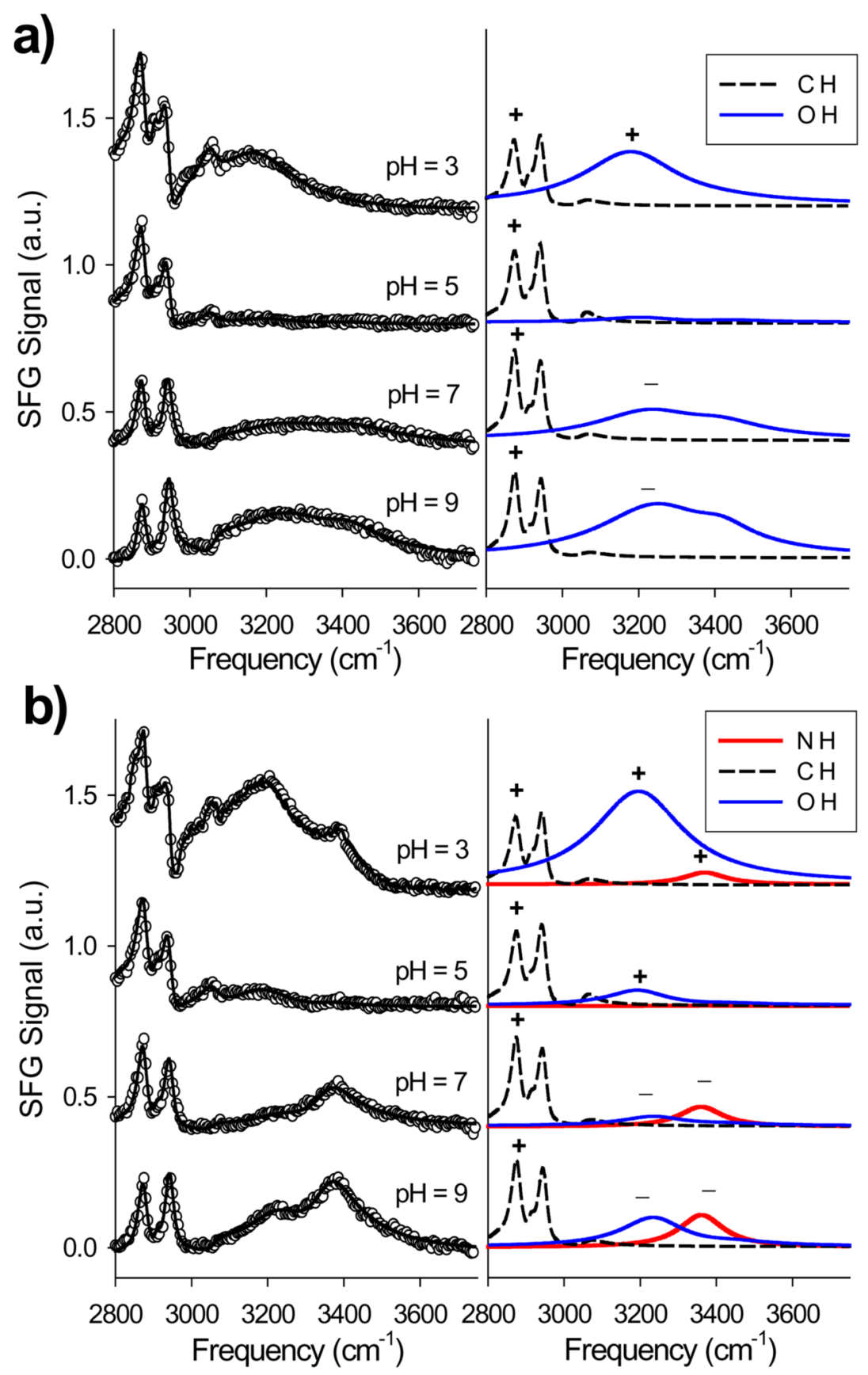

Figure 1.

The VSFS spectra of BSA in (a) $0 \mathrm{M}$ urea and (b) $8 \mathrm{M}$ urea solutions at various pH values. The open circles in the left column are experimental data and the solid lines are theoretical fits. The curves in the right column are the $\mathrm{NH}$ (red), two $\mathrm{OH}$ (blue), and six $\mathrm{CH}$ (black, dashed) components from the fits. The positive and negative signs represent the relative direction of the transition dipole moment of the corresponding vibrations. The frequency and oscillator strength for each component are provided in the Supporting Information. 
a) High pH

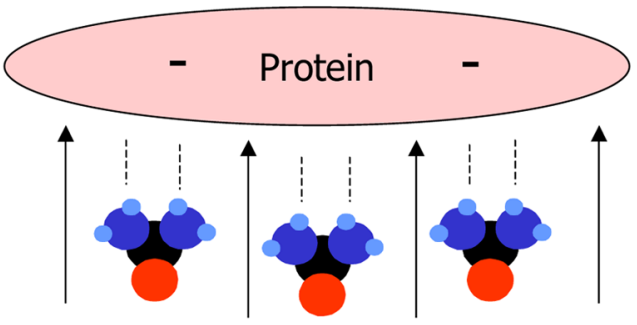

b) Low pH

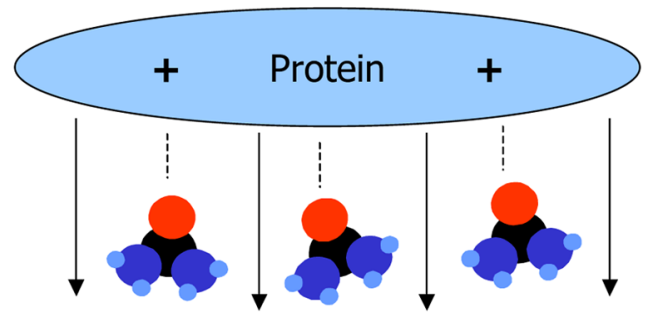

Figure 2.

Schematic diagram of urea orientation at the protein surface for two different $\mathrm{pH}$ values. The arrows represent the local electric field. 